\title{
Pràctiques mudes, congressos científics, semi- naris de recerca $i$ altres dinàmiques científiques d'oralitat al laboratori i a l'aula
}

\author{
Isabel Besson (ibesson@xtec.cat) INS Bellula (Canovelles) \\ Elisa Goytia (mgoytia@xtec.cat) Col.legi Sagrat Cor (Vic) \\ Martí Miró (mmiro234@xtec.cat) INS Marta Mata (Montornès del Vallès) \\ Jordi Domènech (jdomen44@xtec.cat) INS Vilanova del Vallès, Grup LIEC, Universitat Autònoma de Bar- \\ celona
}

L'ensenyament de les ciències demana una atenció explícita als seus gèneres comunicatius i elements lingüístics. En aquest article descrivim diverses iniciatives per a explorar els gèneres comunicatius orals propis de les ciències, aplicades en diversos contextos $i$ centres educatius. Les experiències es descriuen juntament amb una valoració de la seva aportació a aspectes com la modelització o l'adquisició d'habilitats científiques, i s'usen de punt de partida per a valorar quines aportacions fa l'oralitat a les ciències, i proposar indicacions per a promoure-la a l'aula de ciències.

Paraules clau: Comunicació oral, modelització, argumentació, habilitats científiques, gèneres comunicatius

Communication and linguistic aspects are key elements in Science Education. In this article we describe science education activities from several contexts and schools, exploring the oral communication genres of science. We evaluate the importance of oral communication in sciences, especially to develop scientific skills and modelling, and propose advices to develop oral communication events in science classrooms.

Keywords: Oral communication, modelling, argumentation, scientific skills, communicational genres

\section{INTRODUCCIÓ}

És evident que el llenguatge juga un paper clau en el procés de construcció del coneixement per part de l'alumne, i, en particular, en l'aprenentatge de les ciències (Santmartí, 1996, Sanmartí et al, 1999,). Les deficiències tant en l'expressió oral com en l'escrita, així com en el llenguatge bàsic de les ciències suposen un obstacle important per l'aprenentatge de les ciències, fins i tot molt més gran que les deficiències detectades en els continguts procedimentals i conceptuals (Hernández i Hernández, 2011). De fet, a sisè de primària prop de la meitat dels alumnes tenen dificultats per a identificar a què es refereixen expressions com "un fenomen" o "un fet" o per a usar connectors gramaticals del tipus "per una banda...per l'altra", que els poden servir de guia en processos de selecció o interpretació d'informació (Ruano et al., 2011).

Malgrat que a l'aula de ciències sovint semblem confiar en un assoliment espontani de la competència lingüística, Cummins (1984) descriu que, encara que l'alumnat sigui competent en situacions comunicatives col-loquials (BICS, Habilitats Comunicatives Interpersonals Bàsiques), el desenvolupament de la competència comunicativa en contexts acadèmics ( $C A L P$, Competència Cognitiva en Llenguatge Acadèmic) requereix esforços específics, especialment en contexts d'immersió lingüística o d'aprenentatge en segones llengües (L2). Determinats aspectes de la CALP científica només es poden promoure des de les àrees científiques, perquè es corresponen a gèneres lingüístics propis del context científic. Ensenyar ciències no vol dir úni- 
cament fer experiments, sinó que també cal comunicar científicament, exposar idees i discutir-les, proposar hipòtesis, plantejar preguntes, interpretar resultats, interpel-lar models, etc. (Hodson, 1994), raó per la qual aspectes com l'argumentació i la comunicació científica són àmpliament presents en els currículums de les matèries de ciències (Sanz, 2012). Per altra banda, no s'ha d'oblidar que treballar l'expressió oral en l'aprenentatge de les ciències comporta, alhora, aprendre a expressar-se de manera correcta, fet que permetrà als alumnes, en un futur, establir bones relacions socials, personals i professionals (Vilà, 2011a).

Les dificultats en l'aprenentatge lingüístic en les ciències impliquen, per una banda, els propis continguts - la dificultat dels termes i de les relacions semàntiques entre ells- $i$, per l'altra, les formes d'interacció a l'aula que depenen de l'estructura de les activitats i de les estratègies que posa en pràctica el professor pel desenvolupament del tema o patró temàtic (Sanz, 2012, Lemke, 1997). Aquestes formes d'interacció poden ser: explicar el procediment que han seguit els alumnes per resoldre un exercici, potenciar el diàleg entre alumnes, proposar debats, etc. , però, com veurem en aquest article, també poden incloure dinàmiques específiques dels contextos científics, com els congressos científics o el treball al laboratori.

Malgrat tots aquests arguments, l'atenció i exigència del llenguatge en les classes de ciències sovint no és l'adequada i és freqüent observar en els exàmens respostes curtes, amb poques frases explicatives, amb monosíllabs com a resposta 0 amb frases incompletes (Martín, 2013). A més, si l'ús del llenguatge escrit sovint és escàs, quan es tracta de l'expressió oral, observem que l'alumnat té poques oportunitats d'elaborar el seu discurs oral a les classes de ciències (bàsicament es redueix a respostes curtes a les preguntes que anem formulant mentre realitzem la exposició a l'aula i a alguna presentació per part dels alumnes, sovint, descontextualitzada dels gèneres lingüístics científics), i se li proporcionen pocs suports i models perquè pugui millorar. Tot $\mathrm{i}$ que hi ha una certa tendència a menystenir la comunicació oral, el cert és que, de les quatre competències comunicatives que es poden definir (gramatical, discursiva, sociolingüística i estratègica) (Canale, 1983), les dues darreres s'exerciten principalment en la comunicació oral, ja que inclouen les regles socioculturals d'ús de la llengua i la complementació d'estratègies de comunicació verbal i no verbal.
El grup de treball EduWikiLab ${ }^{1}$ és un grup d'innovació en l'ensenyament de les Ciències format per professors i mestres de diversos centres educatius, i durant el curs 2013-2014 ens hem proposat desenvolupar i/o analitzar l'aplicació de diverses dinàmiques/escenaris didàctics d'oralitat a l'aula de ciències, dissenyades amb l'objectiu de millorar l'aprenentatge de les ciències i vinculades als gèneres lingüístics científics en relació a la construcció del coneixement científic.

\section{1) Pràctiaues mudes: Construir un model a nartir de dades i elaborar guions de pràctiques.}

Aquesta experiència didàctica es va dur a terme el curs 2013-2014 amb un grup de 18 alumnes de $2 \mathrm{n}$ d'ESO de l'Escola Sagrat Cor en una matèria optativa anomenada "Petites Investigacions" que consta d'una hora lectiva per setmana i es desenvolupa al laboratori. La matèria té per objectiu complementar mitjançant activitats pràctiques els continguts del currículum de Ciències de la Naturalesa i millorar la competència científica de l'alumnat que tria aquesta optativa.

En el funcionament habitual, els alumnes treballaven un seguit de pràctiques de laboratori en què el guió venia donat i predeterminat pel professorat, de manera que, tot i que no redactaven completament les fitxes guió de cada pràctica, estaven familiaritzats amb els apartats de què consta cadascuna d'elles (títol, introducció, marc teòric, objectius, material, procediment, resultats i conclusions) i el tipus de contingut que configura cadascun dels apartats. Es tractava d'un aprenentatge eminentment centrat en el professor, que triava quines activitats fer, preparava els guions de les pràctiques, explicava a l'alumnat el procediment de cada pràctica i establia els resultats esperats en cada ocasió.

És en aquest context que es va proposar a l'alumnat canviar els rols i passar a un ensenyament més centrat en l'alumnat: les Pràctiques Mudes. En aquestes pràctiques, el professor reprodueix mímicament el procés de la pràctica sense poder parlar en cap moment i l'alumnat ha de discutir oralment què fa el professor -i per què ho està fenti finalment redactar amb posterioritat el guió corresponent a la pràctica per a dur-la a terme. Es va treballar en grups de 3-4 alumnes i es decidí que quan acabés l'activitat es faria una sessió de coavaluació on es triaria el millor guió de la pràctica

\footnotetext{
1 Grup de Treball EduWikiLab http://eduwikilab.wordpress.com/
} 
que serviria com a referent per al disseny de propers guions de pràctiques i que, a més, es portaria a terme amb els alumnes del proper curs de la matèria. Per gestionar l'ordre en les aportacions orals dels estudiants s'escollí entre tots un moderador que va organitzar el torn de paraula en tot moment mentre es duia a terme la pràctica i que anotava quins alumnes participaven en l'explicació oral i si ho feien de forma adequada (Les aportacions són científiques? Es respecta el torn de paraula?).

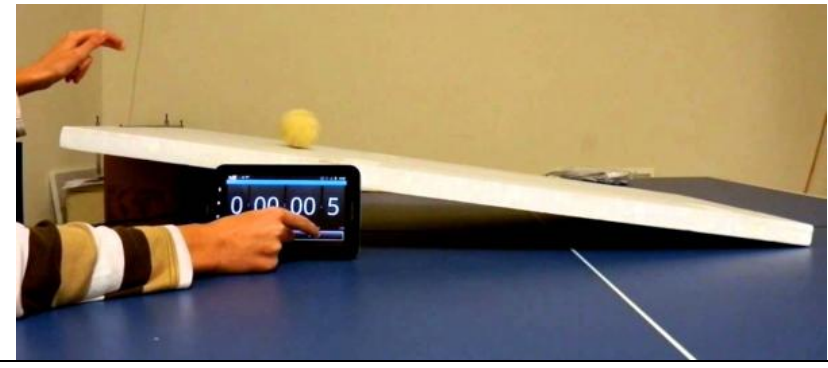

Figura 1. Imatge modificada d'un vídeo que descriu un muntatge experimental similar a l'utilitzat en la Pràctica

Muda

http://www.youtube.com/watch?v=T41PeuFt-5Q

El procediment que la professora va representar mímicament es correspon a una pràctica de tipus investigador (Besson et al, 2012) i es tracta d'analitzar el descens de dos objectes amb diferent massa i superfície de contacte per un pla inclinat per intentar deduir quins factors afecten la velocitat de descens dels objectes per la rampa. Amb anterioritat, els alumnes ja havien portat a terme una pràctica de càlcul de velocitat "Corre, corre $i$ calcula" que es troba disponible a la plataforma de pràctiques de laboratori d'EduWikiLab ${ }^{2}$.La professora va representar el procés, mostrant clarament els objectes que s'usen, mentre els alumnes discutien el significat i objectiu de cada gest o moviment. Un cop acordat entre ells la pràctica, en van redactar el guió i la van dur a terme, amb interessants impactes en el desenvolupament de la pràctica: el fet que l'activitat estigués més centrada en l'alumne (ells expliquen què passa, es corregeixen entre ells, redacten un guió que servirà com a model per a properes sessions...) va fer que l'atenció del grup, la participació i la motivació augmentessin. Cap altre dia hi ha hagué més silenci i ordre a l'hora de parlar i fer aportacions, i fins i tot els alumnes van proposar que hi hagués una altra pràctica muda triada per ells on també un d'ells fes de "professor mut".

2 Plataforma de pràctiques de laboratori EduWikiLab https://eduwikilab. wikispaces.com/Corre,+corre+i+calcula
Igualment, donat que l'alumne/a és el centre de la pràctica, i són ells els qui expliquen què està passant al laboratori, augmenta el grau de consciència dels errors que cometen, ja que reben retroacció dels seus companys, que corregeixen el vocabulari quan no és prou específic, milloren les descripcions dels processos quan no són prou clares, qüestionen les conclusions que no es corresponen amb els resultats de l'experiment, etc. i valoren més les correccions que es van fent durant el procés a l'aula si són ells mateixos els que construeixen el coneixement i no els ve donat de manera unidireccional des del professor.

Des del nostre punt de vista, aquesta metodologia per a presentar les pràctiques de laboratori, a més de proposar un rol més actiu de l'alumnat, fa que mobilitzi concepcions prèvies (sobre els usos dels aparells, pràctiques anteriors,...) per a interpretar les observacions (els moviments de la professora), creant un model mental propi del funcionament i objectius de la pràctica, que contrasta amb les perspectives $\mathrm{i}$ opinions dels companys fins a un model-consens, reproduint així una situació de creació del coneixement científic i incidint en un procés habitualment poc satisfactori, com és la lectura i aplicació de protocols de laboratori.

Tot i que les opinions dels alumnes sobre si han après més amb aquesta nova manera de treballar al laboratori no han estat prou consistents, s'ha pogut constatar que amb aquesta metodologia la qualitat de les memòries de pràctiques entregades per els alumnes ha millorat notablement pel que fa a correcció formal i comprensió de la pràctica.

\section{2) Conaressos cientifics escolars: Comunicar i justificar científicament.}

Es va proposar a 55 alumnes de 4t ESO dels INS Marta Mata (Montornès del Vallès) i INS Vilanova (de Vilanova del Vallès) -cursos 2012-2013 i 2013-2014- participar com a científics en un congrés científic escolar en el que van assistir investigadors d'institucions de recerca. En el congrés, com a part d'una activitat d'indagació ${ }^{3}$, els alumnes presentaren en forma de pòsters científics les seves recerques sobre l'evolució d'uns organismes imaginaris, i dugueren a terme converses amb els investigadors per a justificar els seus resultats $i$ conclusions (Domènech, 2014). Com a bastida didàctica, es proporcionaren als alumnes iniciadors de frase i connectors gramaticals (ja que, en con-

3 Chasing Caminalcules, evolució i estratigrafia https://sites.google.com/a/xtec.cat/caminalcules/ 
seqüència, així doncs,...) com a suport per a elaborar el seu discurs científic ${ }^{4}$.

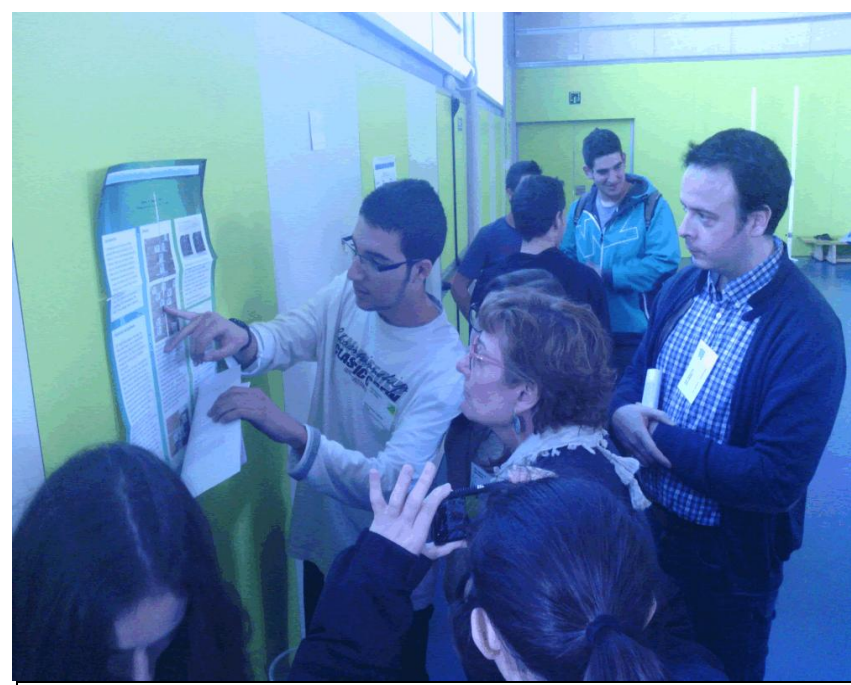

Figura 2. Moment del congrés científic a l'INS Vilanova on un alumne argumenta oralment les seves conclusions als investigadors convidats, els doctors Neus Cols i Cristian Cañestro, de la Universitat de Barcelona.

En parlar de l'experiència amb els alumnes, van destacar el realisme de l'esdeveniment (contextualització), i que el fet de re-elaborar oralment el discurs els feia repensar perquè havien arribat a les conclusions presentades al pòster. Exposar oralment de manera informal (no assajada) una explicació científica obliga els alumnes a cicles repetits entre el que diuen i el que pensen, de l'explicació concreta al model al que fan referència. La necessitat de comunicar amb investigadors reals aliens a la preparació de l'activitat (congrés), fa que els alumnes hagin de recuperar el model i vocabulari científics en un context oral on hi ha molta interacció, incertesa (no sabem què preguntarà, ni si ens entendrà, ni si compartim tot el vocabulari), hi ha interrupcions del discurs i gestualitat i força una recontextualització ràpida dels models a explicar en resposta a aquesta incertesa. Considerem que això és una via de millora en la comprensió dels models per part de l'alumnat.

4 Bastides didàctiques per a comunicar amb pòsters científics:

https://sites.google.com/a/xtec.cat/c3/activitats-decomunicacio-cientifica/posters-cientifics

\section{3) Seminaris de recercas Dissenvar i discutir experiments al laboratori}

Es va proposar a 60 alumnes de 2 ESO de l'INS Marta Mata (Montornès del Vallès) -curs 2012/2013- els Seminaris de Recerca, un activitat que reprodueix els seminaris de recerca habituals en Departaments d'Investigació. Aquests seminaris són presentacions orals informals d'investigacions en procés en les que els assistents poden intervenir oralment i fer propostes de millora o comentaris sobre la recerca que se'ls està presentant. En el món de la recerca científica són una via habitual per a aconseguir noves mirades o opinions sobre recerques que es troben en curs.

En l'activitat escolar, els alumnes, repartits en equips de 3 , havien de dissenyar, cada equip, un experiment per a demostrar algun tipus de tropisme en les plantes. Un cop obtingudes les dades, els alumnes havien de presentar oralment, i de manera informal, partint només de les fotografies dels seus experiments, els seus resultats a la resta del grup de pràctiques (15 alumnes) i discutir-los oralment amb els seus companys, de manera que es presentaven cinc investigacions. Com a condicions, s'establí que com a material de suport només es podrien usar fotografies (no presentacions multimèdia) i que durant l'explicació els companys podien interrompre, per a demanar més informacions, expressar el desacord, o fer propostes.

Es comunicà que el professor (que no participava en la conversa) valoraria i puntuaria tant les explicacions com les participacions, en particular les que ajudin a analitzar l'experiment (proposar controls, evidenciar dissenys incorrectes, ...) o treure conclusions de les dades (incloses conclusions no esperades).

Com a bastides didàctiques, es van proporcionar als alumnes dos documents que s'havien treballat a l'aula anteriorment per a l'expressió escrita. Per una banda, una taula de desenllaços (una taula amb connectors gramaticals que ajuda a explicitar les relacions entre els tractaments realitzats, les expectatives i les conclusions) i per l'altra, una bastida didàctica per a articles científics (també amb diversos connectors gramaticals i iniciadors de frase útils per a expressar-se). Ambdues bastides són disponibles per a la seva descàrrega ${ }^{5} \mathrm{i}$ ja havien

5 Taules de desenllaços per a dissenyar experiments https://sites.google.com/a/xtec.cat/c3/dissenyemexperiments i Bastides didàctiques per a articles científics escolars 
estat usades per aquests alumnes en experiències descrites anteriorment (Domènech, 2013a i b).

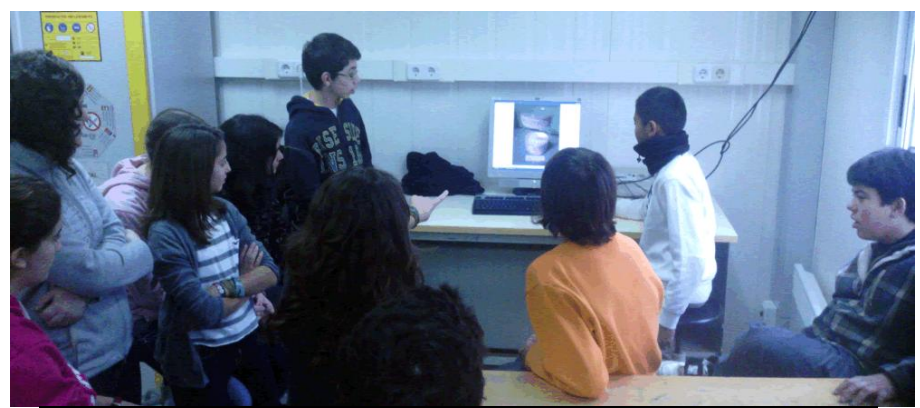

Figura 3. Moment d'un dels seminaris de recerca celebrats. El professor (fotògraf) es manté explícitament com a observador extern.

Al llarg de les exposicions, el professor va fer servir una taula amb columnes per a les diverses habilitats científiques (comprendre i dissenyar experiments, fer hipòtesis, extreure conclusions de dades, argumentar) per a marcar els tipus d'intervencions en el debat i qui les feia, però sense participar-hi més enllà de subratllar les bones participacions o aportar algun terme de vocabulari específic (principalment, referent al disseny d'experiments: control, variable, hipòtesi,...). Després de cada exposició, el professor fa un comentari general de la conversa, en general dirigit a l'ús adequat de connectors gramaticals: per tant, així doncs, en tot cas, tot i això,...

Tot i que en un inici, l'alumnat semblava excessivament pressionat per la necessitat de fer aportacions rellevants, després de les primeres intervencions es relaxaven i participaven al debat de manera més espontània. En els sis seminaris celebrats, els alumnes es bolquen completament en l'anàlisi dels experiments dels companys, i s'incorporen de manera gradual termes relatius a la investigació com control, tractament o factor, o específics del tema com tropisme positiu/negatiu.

Durant els seminaris, fins i tot la disposició a l'aula va ser informal. Es va procurar transmetre l'alumnat que en aquest moment se'l considerava un expert en investigació, i que, per tant, es deixaven de banda convencions escolars (no interrompre, seure ordenats, no moure's,...) per a prioritzar un diàleg el més obert possible. El professor quedava fora del cercle format pels alumnes, com a observador de les discussions, anotant participacions i participant només ocasionalment per a subrat-

https://sites.google.com/a/xtec.cat/c3/activitats-decomunicacio-cientifica/articles-cientifics llar positivament idees o arguments, en la línia del que proposen altres autors (Finkel, 2008).

El professor valora l'experiència molt positivament, perquè va permetre en el marc d'una hora de classe generar una dinàmica de coneixement en l'aula en la que els alumnes es situaren en el rol d'experts, i de la que en surten qualificacions respecte habilitats científiques que són difícilment avaluables. Així mateix, el format oral va evidenciar que alumnes que sovint no entreguen les pràctiques escrites tenen actituds i habilitats científiques rellevants, quelcom que no se'ls valora habitualment. Alumnes i professor vam coincidir en que la situació del docent com a observador extern havia estat còmoda i interessant.

Els alumnes destacaren principalment que se'ls posava nota per parlar (quan en general se'ls demana que callin) i que com que podien interrompre, estaven més atents i entenien millor el que s'estava explicant. De manera general, estaven d'acord en que amb aquesta activitat havien après com calia dissenyar experiments, que analitzar els resultats era una feina difícil, i que fer d'experts els feia sentir bé amb la feina que feien. El lector trobarà d'interès els vídeos d'una aproximació similar duta a terme per altres autors (Martín, 2013) ${ }^{6}$.

\section{4) Presentar receraues i construir hi- nòtesis a partir de preguntes espon- tànies}

El curs 2013-2014, en el marc de la unitat didàctica sobre reproducció sexual de la matèria de $\mathrm{Ci}$ ències de la Naturalesa, es va demanar a 18 alumnes de $3 r$ d'ESO de l'Institut Marta Mata de Montornès del Vallès, que en grups de 2 o 3 persones preparessin $\mathrm{i}$ exposessin oralment una petita presentació sobre alguns dels apartats de la Unitat Didàctica "Reproducció sexual": aparell reproductor masculí, aparell reproductor femení, cicle menstrual femení, malalties de transmissió sexual, mètodes anticonceptius i sexe i sexualitat. Els alumnes havien de buscar informació en diferents fons (llibre de text, internet, entrevista amb la infermera del centre...) per tal de documentar-se. Es van dedicar fins a 3 sessions per a que l'alumnat busqués informació a l'aula d'informàtica i a assessorar els diferents grups sobre els aspectes que haurien de tractar a cada apartat. Tot i que inicialment la proposta es va rebre per la majoria de grups amb interès, amb la premissa que els alumnes passarien

6 Vídeos hablar en el laboratorio (Leer.es): http://www.youtube.com/playlist?list=PL5188B3E2706 6C8CB 
a ser professors i experts del seu apartat, a mesura que passaven les sessions es va diluir l'interès, fins al punt que les exposicions van ser fetes d'una manera apàtica i memorística, en alguns casos sense acabar d'entendre'n el contingut i sense assimilar per part dels oients la informació que la majoria de grups intentaven transmetre.

Aquesta situació entrava en contrast amb altres situacions d'oralitat a l'aula amb els mateixos alumnes en les que una pregunta d'algun alumne evidenciava algun conflicte cognitiu i generava una discussió a l'aula on realment la majoria d'alumnes estaven implicats, motivats i predisposats al debat i la participació. Aquestes "converses espontànies" partien de la seva observació i curiositat científica d'aspectes quotidians de la seva vida (la taula del menjador de casa seva, el vaixell o avió que han agafat per anar-se'n de vacances) i que volien compartir amb la classe: "Una de les coses que mai he entès és com pot ser que un vaixell que està fet de ferro, pugui surar!"; o "Com pot saber la meva mare que la sopa calenta ho està més al mig del plat que no pas a les vores? Em diu que comenci pel costats i té raó!"; o "Per què els iogurts que menjo a la casa de colònies quan vaig a la neu estan com inflats?".

Les converses espontànies apareixen com un dels punts més valorats pels alumnes en fer la revisió del curs, ja que acostumen a ser moments en els que les aportacions de cadascú són escoltades i analitzades amb detall, i sovint rebatudes; moments en els que el professor passa a ser un simple moderador i fins i tot, només un oient passiu. Pensem que els alumnes estan possiblement cansats i saturats de fer exposicions orals (a moltes matèries en algun moment del curs les fan, i també als Crèdits de Síntesi i Projecte de Recerca) per dues raons: per una banda, potser els interessos de l'alumnat i el que nosaltres creiem que els pot motivar no coincideix, i el fet que el professor plantegi i esculli un tema interessant des del seu punt de vista, ja li treu interès al tema. En aquest sentit, una proposta podria ser que els propis alumnes que proposessin (de manera natural i puntual) els temes sobre els que volen aprofundir o desenvolupar algun treball. Per altra banda, sovint en les presentacions orals demanem una mera descripció o re-presentació, enlloc de la resolució d'un conflicte cognitiu, que permetria que els alumnes es posicionessin en un debat més participatiu i en el que s'incitaria de manera més forta la interpel·lació d'un model científic que expliqui la situació de conflicte.

Els temes tractats en aquestes "converses espontànies" sovint no poden preveure's, però sí que caldria tenir un pla d'acció de com i quan treballarles i acompanyar-les quan apareixen, ja que de vegades aquest tipus de comunicació oral es pot quedar en una simple conversa interessant que ajuda a satisfer de manera immediata la curiositat $i$ prou. En el nostre cas, aquestes converses s'han reconduït a exposicions orals voluntàries ("El nombre d'or", "Què són els quarks de la matèria?"...) i l'elaboració de vídeos científics ("Com mesurar l'alçada d'un edifici amb la trigonometria?") 7.

\section{5) Guies científics al Museur Usar evidències i contextualitzar-les en un període geològic}

Aquesta dinàmica es va proposar el curs 20132014 a 33 alumnes de I'INS Vilanova del Vallès en el marc del currículum de Biologia i Geologia de $4 \mathrm{t}$ d'ESO, amb l'objectiu de relacionar els models científics sobre l'evolució de la vida a la Terra amb els continguts d'una visita a l'exposició "Planeta Vida" sobre el mateix tema al Museu de Ciències Naturals de Barcelona (Museu Blau). El alumnes de la matèria es van encarregar d'organitzar la logística (transport, orientació,...), però també la realització de la visita: cada equip de 3 alumnes es preparava un període geològic de l'evolució de la vida a la Terra, per, un cop a la visita, explicar-lo fent servir els materials de l'exposició que hi fessin referència.

Durant la visita, els alumnes havien de cercar les evidències que feien referència al seu període i relacionar-les amb les característiques del seu període per a poder-los explicar.

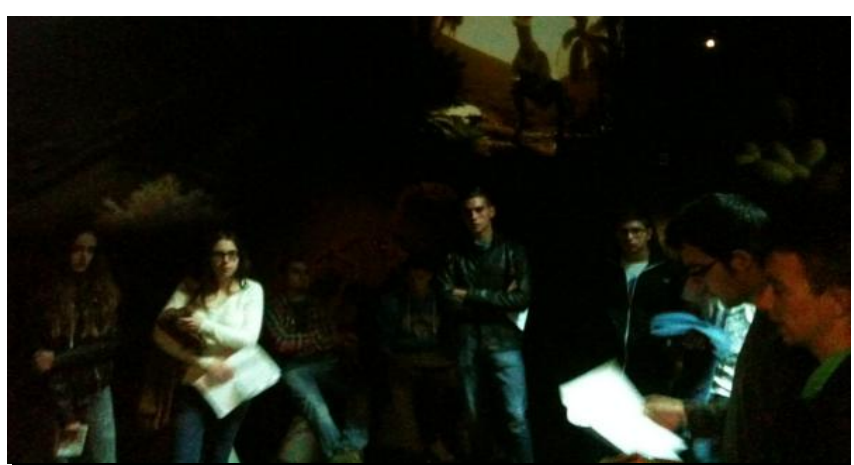

Figura 4. Moment de la visita al Museu Blau: els alumnes han de relacionar la informació que han recollit amb les evidències que hi estiguin relacionades.

7 Vídeo científic realitzat pels alumnes i presentat al concurs VídeoMat, aplicant la trigonometria al càlcul de l'alçada d'un edifici

https://www.youtube.com/watch?v=FGuKc00bwg\&list=UUg9eizkWx690sNH5t_VI58Q 
A més de requerir un domini no memorístic del període en qüestió, l'activitat promou la interpretació d'evidències en diferents formats (fòssils, pòsters, vídeos) en funció del que ja saben. La proposta didàctica segueix les indicacions d'altres autors i experiències anteriors (Guisasola et al, 2005), en el sentit de proposar un marc d'activitats (anterior i posterior) contextualitzant la visita al museu, i inclou un conflicte cognitiu, ja que implica que els alumnes formulin una presentació oral in situ en un context $i$ identificant quins objectes poden servir d'evidències. El format de l'activitat (exposicions breus alternades amb deambulació en l'exposició) promou també que els alumnes parlin entre ells de manera informal per a localitzar evidències: "Has vist algun estromatòlit?" "Allà he trobat fòssils de nummulits".

\section{6) Debats a I'aula. Araumentar cientí- ficament dilemes sòcio-científics.}

Per a millorar la comunicació oral i l'argumentació científica dels alumnes, i partint de propostes prèvies (Solbes et al, 2010, Trinidad, 2010) es va elaborar un taller d'argumentació científica incidint en l'estructura lògica de l'argumentació. La pràctica per escrit -duta a terme a partir de l'anàlisi de textos sobre evolució- es va completar amb un debat organitzat a l'aula sobre els transgènics, usant com a punt de partida dilemes sòcio-científics d'un taller proposat per altres autors (Albaladejo et al, 2009), incloent també aspectes de l'argumentació no estrictament relacionats amb l'estructura lògica competència discursiva-, sinó com a pràctica social -com cedir la paraula, incloure les idees dels altres,... (Vilà i Castellà, 2012)-, competència sociocultural. L'activitat s'ha dut a terme el curs 20132014 amb 2 grups de 17 alumnes de 4t d'ESO de I'Institut de Vilanova del Vallès.

La pregunta central del debat proposava un dilema segons el qual es pretenia plantar, de manera experimental, blat transgènic en camps del municipi, aportant llocs de treball al municipi. La tasca dels alumnes fou prendre una posició a favor/en contra en base a diverses informacions incompletes extretes dels textos llegits (capacitat de colonització del blat, possibles efectes tòxics/al-lergògens, impacte econòmic i social,...). Tot seguit, es va iniciar el debat: els alumnes es distribuïren lliurement entre dos equips (que en els dos grups-classe resultaren ser bastant equilibrats) separats físicament a l'aula. En tot moment, es mantingué a la pissarra de l'aula dues taules per a cada equip, que mesuraven el tipus de participacions i el tipus d'arguments.

\begin{tabular}{|l|l|l|}
\hline \multicolumn{2}{|l|}{ A: PEL TALLER D'ARGUMENTACIÓ } \\
\hline Com que... & DADES & $\begin{array}{l}\text { Coses que observes (dades, no opini- } \\
\text { ons!) i que, en principi són compartides } \\
\text { sense discussió }\end{array}$ \\
\hline i.... & JUSTIFICACIÓ & $\begin{array}{l}\text { Relació entre el que observes i el que } \\
\text { pretens afirmar }\end{array}$ \\
\hline $\begin{array}{l}\text {...i es com- } \\
\text { pleix de for- } \\
\text { ma general } \\
\text { que... }\end{array}$ & GARANTIA & $\begin{array}{l}\text { Norma general acceptada per tothom } \\
\text { que fa que la justificació sigui sòlida. } \\
\text { Defineix un context en el que la justifi- } \\
\text { cació es compleix necessàriament. }\end{array}$ \\
\hline $\begin{array}{l}\text { Llavors, con- } \\
\text { cloc que... } \\
\text { En conse- } \\
\text { qüència... }\end{array}$ & CONCLUSIÓ & \begin{tabular}{l} 
Conclusió que defenses. \\
\hline $\begin{array}{l}\text { A menys } \\
\text { que... }\end{array}$
\end{tabular} \\
\hline $\begin{array}{l}\text { REFUTACIÓ } \\
\text { B: PEL DESENVOLUPAMENT DEL DEBAT }\end{array}$ & $\begin{array}{l}\text { Defineix un context en el que la justifica- } \\
\text { ció ja no valdria. És el contrari de la Ga- } \\
\text { rantia. Circumstàncies o situacions en les } \\
\text { que no es trauria aquesta conclusió. }\end{array}$ \\
\hline
\end{tabular}

Tipus de participació

$+$

Aportar noves dades o punts de vista.

Argumentar a partir d'evidències.

Recollir/completar aportacions d'altres.

Proposar consensos, totals o parcials.

Tipus d'arguments

Socials

Cientifics

Econòmics

Altres

Donar opinions no fonamentades 0 introduir

aspectes irrellevants

Interrompre, cridar o faltar al respecte

Tergiversar 0 deformar aportacions d'altres participants

Figura 5. Materials i bastides usades en el taller d'argumentació (a) i per al desenvolupament del debat (b). Els materials del taller d'argumentació són disponibles a internet ${ }^{8}$. Les dues taules del debat promouen l'ampliació dels tipus d'arguments (científics, socials, econòmics,...) I la millora de la qualitat de les participacions.

Al llarg del debat, el professor no va intervenir ni per a moderar-lo, ni per a corregir argumentacions, es va limitar a marcar a la pissarra quin tipus de participacions o arguments s'estaven produint, amb símbols positius o negatius, que els alumnes van identificar per si mateixos com a penalitzacions/reconeixements. Tot i que en un inici els alum-

8 Taller d'argumentació a l'aula de Ciències https://sites.google.com/a/xtec.cat/c3/argumentaciocientifica 
nes feien atenció al tipus d'arguments, ben aviat es centraren en el tipus de participació.

Al llarg del debat, les argumentacions valorades positivament (específicament, les referències a arguments que havia aportat a algú altre) van augmentar gradualment. Els alumnes no van arribar a un consens, però sí que es van posar d'acord en que necessitaven més dades per a prendre decisions, enunciant en diverses ocasions frases condicionals: "Si sabéssim si es poden aillar bé els camps..." "Si sabéssim quin és l'efecte en el preu del blat normal,...", que constitueixen, en el fons, en dissenys primaris d'experiments.

Durant la conversa, es van detectar diverses concepcions errònies (que els gens viatgin per l'aire d'una planta a l'altra, o que el blat transgènic sigui més car) que van ser corregides per els mateixos companys. El lector trobarà d'interès propostes d'altres autors al voltant del debat i l'argumentació a les aules de ciències (Vilà i Castellà, 2012) i la importància dels dilemes sòcio-científics no només com a contextualització, sinó també com a incitació a la reflexió sobre la naturalesa de la ciència (España i Prieto, 2010), que considerem que es promou en aquestes activitats.

\section{DISCUSSIÓ I CONCLUSIONS}

Es fa difícil fer un balanç general d'activitats tant diverses, però, a partir del que hem observat, considerem que aquestes dinàmiques orals d'aprenentatge de la ciència que donen la paraula als alumnes ofereixen diversos avantatges:

- Permeten evidenciar concepcions errònies, ja que moltes d'elles requereixen que l'alumnat formuli explicacions a partir de les evidències $i$ els models abstractes de què disposa. Quan el professor és el que parla, aquestes concepcions no apareixen. El format oral permet l'expressió més evident d'emocions, importants en la creació del coneixement científic.

- Promouen la participació i implicació d'alumnat que no participa o fracassa en altres activitats (per exemple, la redacció d'informes escrits) i permet avaluar-los des del punt de vista de la competència científica, donant oportunitats a alumnes que, simplement, tenen problemes amb les activitats escrites.

- Agilitzen pràctiques i activitats científiques que altrament serien difícils, o impossibles de dur a terme.

- Permeten incorporar concepcions i coneixements previs i negociar significats amb l'alumnat.
- Impliquen la pràctica de cicles ràpids d'observació-expectatives-resultats-model de manera explícita, constituint un modelatge de raonament científic.

- Generen un clima de creació del coneixement a l'aula en el que el contrast de models i l'argumentació esdevenen un hàbit, en el que el professor deixa el paper principal de narrador.

- De la discussió sobre el que hem observat, proposem diversos elements que ens han semblat importants a l'hora d'aplicar dinàmiques d'oralitat en l'ensenyament de les ciències:

- La connexió a models científics és molt més eficaç quan la conversa s'orienta a la resolució d'un conflicte cognitiu, que per a resoldre'l necessiti aclarir o matisar el significat de les observacions o funcionament dels models.

- L'ús de bastides didàctiques lingüístiques orientades als gèneres discursius específics de la ciència dóna als alumnes seguretat i eines per a millorar la seva competència lingüística en ciències. (Domènech, 2013a, 2013b)

- Convé incloure en les activitats referències a objectes o contextos concrets que puguin servir de referència per a connectar els termes de vocabulari amb els conceptes o models científics que encarnen.

- És important comunicar a l'alumnat de manera explícita els objectius d'aquestes activitats, no només en termes d'oralitat, sinó també en termes d'empoderament de l'alumnat com a creador de coneixement, i tenir present la dificultat que significa per a l'alumnat parlar de coneixement en termes d'igualtat amb el professorat i la necessitat de crear un clima de confiança a l'aula (Finkel, 2011, Vilà, 2011a).

- Cal mantenir el vincle de les activitats d'oralitat a gèneres lingüístics científics, ja que comporten una mirada científica sobre els fenòmens (per l'estructura lingüística o les eines gramaticals).

- Convé aprofitar el vessant lúdic que comporten aquestes activitats per a promoure una relació sana dels alumnes amb el coneixement científic.

- En la programació didàctica cal establir sistemes o criteris d'avaluació i qualificació que incloguin la comunicació oral i compartir-los amb els alumnes (Vilà, 2011b, Sanmartí et al, 1999). Aquests poden fer referència a competències comunicatives gramaticals (ús adequat dels connectors gramaticals), però també a les altres competències comunicatives esmentades a la introducció (discursiva, sociolingüística i estratègica) (Vilà, 2011b, Canale, 1983), incloent la coherència del discurs, l'ús adequat de gestos o objectes per a modelitzar conceptes científics en la conversa 
oral,...i evitant incloure massa ítems o ítems massa genèrics en una mateixa activitat.

- És important modular la participació del professor en les converses, ja que convé limitarla al mínim possible i dirigir-la fonamentalment a fer que els alumnes desenvolupin les idees més que corregir-les directament. Davant una afirmació incorrecta, preguntar "Perquè penses això?" o "Què t'ho fa pensar?" ens pot permetre identificar les concepcions errònies que estan a la base d'aquests errors. Ruano et al (2011) proposen una interessant classificació de les intervencions docents (regulatòria, no invasiva, invasiva, de feedback) que exemplifica diversos iniciadors de frase ("Intenta dir-ho amb altres paraules...", "Per tant,...") que ens semblen una bona via per a progressar en aquest sentit.

Creiem que en conjunt les dinàmiques proposades són útils perquè els alumnes connectin models científics amb els fenòmens que els representen. Al mateix temps, constitueixen vies àgils per a modelitzar a l'aula de ciències, una necessitat que han detectat altres autors en les activitats d'indagació (Simarro et al, 2013). El lector pot trobar d'interès altres dinàmiques d'oralitat 0 gèneres discursius proposades per altres autors (Sanz, 2012, Martínez, 2004, Palou i Bosch, 2005). Les experiències presentades s'emmarquen en el treball d'innovació educativa dut a terme al grup de treball EduWikiLab -dirigit els cursos anteriors a la creació d'un espai col-laboratiu sobre pràctiques de laboratori (Besson et al, 2012) i l'avaluació d'habilitats científiques (Goytia et al, 2015)- i el projecte C3 sobre la Creació del Coneixement Científic ${ }^{9}$.

\section{AGRAIIMENTS}

Els autors agraeixen la col-laboració de l'alumnat i professorat dels centres participants (INS Vilanova del Vallès, INS Bellula -Canovelles, Granollers-, INS Marta Mata-Montornès del Vallès-, Escola Sagrat Cor de Vic). Les experiències contingudes en aquest article descriuen part del treball dut a terme pel grup de treball EduWikiLab el curs 20132014 i s'emmarquen en la reflexió metodològica duta a terme en el grup LIEC (Llenguatge i Ensenyament de les Ciències) de la Universitat Autònoma de Barcelona -grup de recerca consolidat (referència 2014SGR1492) per AGAUR (Agència de Gestió d'Ajuts Universitaris i de Recerca) finançat per el Ministero de Educación y Ciencia (referència EDU2012-38022-C02-02)-. Els autors agraeixen el su-

9 Projecte C3 Creació del Coneixement Científic https://sites.google.com/a/xtec.cat/c3/home port del Centre de Recursos del Professorat CRP1 de Granollers, del Departament d'Ensenyament de la Generalitat de Catalunya.

\section{REFERENCIES}

ALBALADEJO, R. BOSCH, M. BOSCH, S. MAYMO, I., MONTOBBIO, M. (2009). Els transgènics a debat, a: "Seguint la pista del DNA". Grup de treball de l'I.C.E. de la U.B. [http://srvcnpbs.xtec.cat/cdec/images/stories/WEB_an tiga/innovacio/pdf/c3/transgenics.doc ]

BESSON, I., DOMÈNECH, J., GOYTIA, E., SÁNCHEZ, N. (2012). EduWikiLab : la creació d'un espai col-laboratiu sobre treballs pràctics al laboratori i al taller. Ciències, 23, 15-20

CANALE, M. (1983). De la competencia comunicativa a la pedagogía comunicativa del lenguaje, pp 63-81 dins M. Llobera (ed) (1995), La competencia comunicativa. Barcelona, Edelsa.

Cummins, J. (1984) Bilingual Education and Special Education: Issues in Assessment and Pedagogy. San Diego: College Hill

DOMENNECH, J. (2013a). Escritura de artículos y diseño de experimentos: andamios para escribir, pensar y actuar en el laboratorio. Enseñanza de las Ciencias, número especial Congreso ENSE Ciencias 2013, 1085-1089.

DOMÈNECH, J. (2013b). Los andamios didácticos: oportunidades y amenazas, una experiencia con exposiciones orales. Aula de Secundaria 3, 2429

DOMÈNECH, J. (2014). Una secuencia didáctica en contexto sobre evolución, taxonomía y estratigrafía basada en la indagación y la comunicación científica. Alambique, Didáctica de las Ciencias Experimentales, 78, 51-59.

ESPAÑA, E., PRIETO, T. (2010). Problemas sociocientíficos y enseñanza-aprendizaje de las ciencias. Investigación en la escuela, 71, 17-24

FINKEL, D. (2008). Dar clase con la boca cerrada. Publicacions de la Universitat de València.

GOYTIA, E., BESSON, I., GASCO, J., DOMÈ$\mathrm{NECH}$, J. (2015). Evaluar habilidades científicas. Indagación en los exámenes. ¿Una vía para cambiar la práctica didáctica en el aula? Alambique, Didáctica de las Ciencias Experimentales, 79, 1-11.

GUISASOLA, J., AZCONA, R., ETXANIZ, M.,MUJIKA, E., MORENTIN, M. (2005). Diseño de estrategias centradas en el aprendizaje para las visitas escolares a los museos de ciencias. Revista Eureka sobre Enseñanza y Divulgación de las Ciencias, 2(1), 19-32

HERNÁNDEZ, L., HERNÁNDEZ, C. (2011) . La expresión oral y escrita como proceso clave en el aprendizaje de las ciencias. Didáctica de las 
ciencias experimentales y sociales, 25, 213222.

HODSON, D. (1994). Hacia un enfoque más crítico del trabajo en el laboratorio. Enseñanza de las Ciencias, 12(3), 299-313.

LEMKE (1997). Aprender a hablar ciencia. Lenguaje, aprendizaje y valores. Barcelona: Paidós.

MARTÍN, M. J. (2013) . Hablar ciencia: si no lo puedo explicar, no lo entiendo. Revista eureka sobre Enseñanza y Divulgación de las Ciencias, 10 (3): 291-306.

MARTÍNEZ, A. (2004). Cómo preparar una exposición oral en todas las áreas de secundaria. Gobierno de Navarra. Blitz serie naranja.

[http://dpto.educacion.navarra.es/publicaciones/pdf/blitzn aranja.pdf]

PALOU, J., BOSCH, C. (2005). La llengua oral a l'escola. 10 experiències didàctiques. Editorial Graó, Barcelona.

RUANO,E.,SÁNCHEZ, E., CIGA, E., GARCÍA, J.R. (2011). Un protocolo para observar cómo los profesores ayudan a sus alumnos cuando leen textos en el aula. Psicología Educativa, 17, 127145

SANMARTÍ, N. (1996).Para aprender ciencias hace falta aprender a hablar sobre las experiencias y sobre las ideas. Textos, 8. 27-40

SANMARTÍ, N; IZQUIERDO, M; GARCÍA, P. (1999) Hablar y escribir: una condición para aprender ciencia. Cuadernos de Pedagogía, 281, 54-58.

SANZ, G. (2012). Aprendizaje y mejora de las habilidades orales. Cuadernos de Pedagogía, 423, 46-49

SIMARRO, C., COUSO, D., PINTÓ, R. (2013). Indagació basada en la modelització: un marc per al treball pràctic. Ciències, 25, 35-43

SOLBES, J., RUIZ, J.J., FURIÓ, C. (2010) Debates y argumentación en las clases de física y química. Alambique, Didáctica de las Ciencias Experimentales , 63, 65-75

TRINIDAD; O. (2010) Producción de argumentaciones escritas en las clases de física. Alambique, Didáctica de las Ciencias Experimentales, 63, 50-56

VILÀ, M. (2011a). Seis criterios para enseñar la lengua oral en la educación obligatoria. En línia a Leer.es: http://leer.es/wpcontent/uploads/publicaciones/PDFs/201112.pdf [30 de juny 2014]

VILÀ, M. (2011b) . La competència oral a l'educació obligatòria. Orientacions bàsiques. Articles de Didàctica de la Llengua i la Literatura, 55, 6983

VILÀ, M., CASTELLÀ, J.M., (2012). Argumentar y debatir con más de 25 en clase. Cuadernos de pedagogía, 423, 55-60 